\title{
THE GROWTH AND DEFORMATION OF ICE CRYSTALS
}

\author{
By J. W. Glen and M. F. Perutz \\ (Cavendish Laboratory, Cambridge)
}

\begin{abstract}
ABSTRACr. X-ray diffraction photographs were taken of ice dendrites grown from water and from the vapour. In both cases [ $11 \overline{2} 0]$ was found to be the growth direction.

A method of growing cylindrical single crystals of any desired orientation has been devised. Some of these crystals were extended to several times their original length. Slip took place exclusively on the basal plane. Experiments designed to locate the glide direction gave inconclusive results and suggested that, in general, crystals near the melting point can glide in any direction.

Before deformation, ice crystals gave fairly sharp X-ray diffraction spots on Laue photographs. After deformation the spots are drawn out into streaks which later break up into rows of small spots. This indicates that bending of the crystals is followed by the formation of small crystallites of slightly differing orientations. Analogous effects are observed in metals.
\end{abstract}

Zusammenfassing. Eisdendriten wurden aus Wasser und aus Wasserdampf gezüchtet. Röntgenbeugungsaufnahmen zeigten, dass die Wachstumsrichtung in beiden Fällen [ $\mathrm{I} \mathrm{I} \overline{2} \mathrm{O}$ ] ist.

Es wird über eine Methode zur Herstellung zylindrischer Einzelkristalle beliebiger Orientierung berichtet. Solche Kristalle wurden auf ein Mehrfaches ihrer ursprünglichen Länge gedehnt und glitten ausschliesslich auf der Basisebene. Experimente zur Festlegung der Gleitrichtung gaben zweideutige Ergebnisse, deuteten aber an, dass Kristalle nahe dem Schmelzpunkt in jeder Richtung gleiten können.

Laue Aufnahmen undeformierter Kristalle zeigen schatfe Röntgenreflexe. Nach der Deformation sind die Reflexe in Streifen ausgezogen, die später in einzelne Flecke aufbrechen. Dies deutet darauf hin, dass sich die Kristalle zuerst verbiegen und später in eine Reihe kleiner Kristalle leicht verschiedner Orientierung verwandeln. Analoge Effekte werden auch in Metallen beobachtet.

\section{INTRODUCTION}

Ice crystals consist of water molecules arranged in layers of hexagonal rings as shown in Fig. I $a$ (p. 398), the molecules in each ring being alternately above and below the layer plane. This structure bears some resemblance to the structure of the hexagonal metals such as magnesium, cadmium and titanium, shown in Fig. $\mathrm{s} b$, although, as will be seen, it is not identical.

Surprisingly, no direct determination of the crystal directions in a snow flake has been made, although some data have been obtained for the analogous case of ice dendrites developing in water. Megaw ${ }^{1}$ found that heavy ice $\left(\mathrm{D}_{2} \mathrm{O}\right)$ grew fastest from the liquid in a $\langle\mathbf{I} \overline{\mathbf{2}} \mathrm{O}\rangle$ direction,* and Owston ${ }^{2}$ observed that the spicules which developed under an ice layer and protruded into the water were elongated in $\left\langle\mathrm{IO}_{\overline{\mathrm{I}}} \mathrm{O}\right\rangle$ directions. The only evidence for the growth direction of ice forming from the vapour has been provided by Mason and Owston, ${ }^{3}$ who measured the orientation of "hopper-shaped" crystals formed in a cold chamber, and found that their faces were $\{\mathrm{I} \circ \overline{\mathrm{I}} \mathrm{O}\}$ planes, which implies that their points, and hence the growth directions, were $\langle\mathrm{I} \overline{\mathbf{2}} \mathrm{O}\rangle$ directions.

In view of these rather indirect and conflicting results, it was decided to try to measure the direction of growth of ice dendrites formed both in water and from the vapour.

A second unsolved problem in the study of ice crystals is the direction in which ice crystals slip when deformed. McConnel ${ }^{4}$ showed that ice crystals slip on the basal plane, but subsequent attempts to find a particular direction of slip have failed. Both Mügge ${ }^{5}$ and Tammann and Salge 6 found no difference in the stress needed to shear ice along various directionis in the basal plane. As metal and other crystals which deform by slip all do so along specific rows of atoms on their slip planes, it was also decided to try to determine these directions by the methods normally used for metals.

\section{The Growth Direction of Ice}

Water dendrites were obtained by allowing a bowl of water to freeze in a refrigerator; the first ice consisted of plate-like dendrites, like the one shown in Fig. 2 (p. 395). One of these was removed, mounted on an X-ray goniometer, and carefully oriented so that it had its growth direction vertical and its plane perpendicular to the X-ray beam. During exposure cold air,

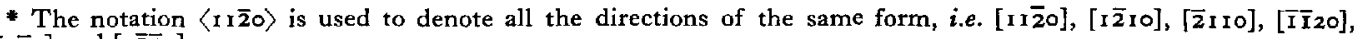
[ $\overline{\mathrm{I}} 2 \overline{\mathrm{I}} \mathrm{O}]$ and $[2 \overline{\mathrm{I}} \overline{\mathrm{I}} \mathrm{O}]$.

$26 *$ 
obtained by boiling liquid air in a vacuum flask, was blown over the specimen. The resulting diffraction pattern (Fig. 3, p. 395) shows the hexagonal symmetry clearly, and allows us to say that this water dendrite was elongated in the $\langle 11 \overline{2} 0\rangle$ directions.

In a similar manner a dendrite grown from the vapour was removed from the walls of the refrigerator, mounted with its axis vertical and X-rayed. Fig. 4 (p. 395) shows the specimen mounted on the goniometer as seen by the X-ray film, and Fig. 5 (p. 395) the resulting diffraction pattern. Owing to the very delicate nature of this specimen, its orientation could not be set so exactly, and the resulting pattern is not so well oriented or so clear as that from the water dendrite. A longer exposure was impracticable because of the large amount of fine frost deposited on the specimen, which could not be blown off as was done with more bulky specimens; this frost is responsible for the small spots on the diffraction pattern. Despite the relative weakness of this pattern it is clear that the vertical growth direction is the same as in the case of the water dendrite, i.e. it grew along the $\langle 1 \mathrm{I} \overline{2} \mathrm{O}\rangle$ directions.

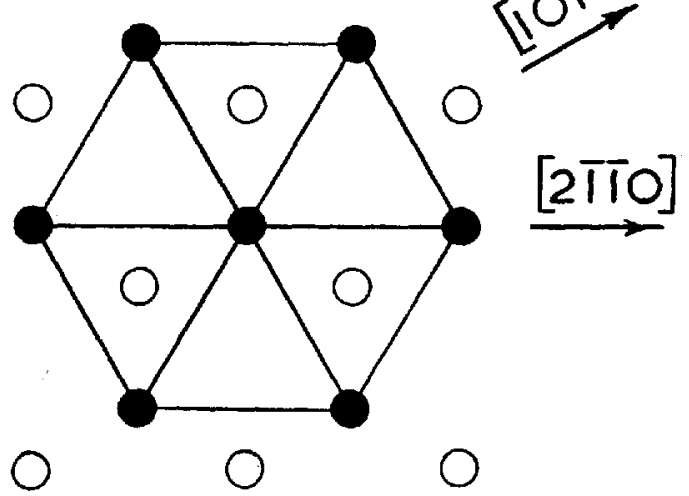

(a)
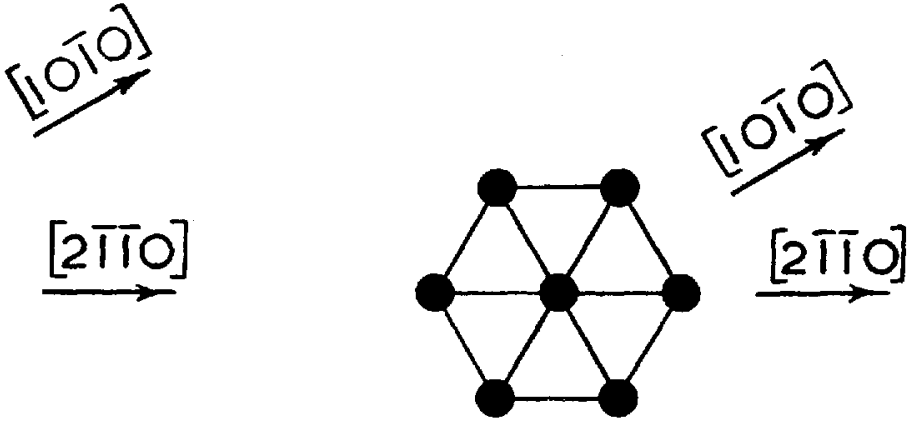

(b)

Fig. I (a). The positions of water molecules in one layer of the ice structure; each circle represents a water molecule. The molecules marked $O$ are above the plane and those marked $\bullet$ are below it. Two principal crystallographic directions are marked

Fig. $I(b)$. The positions of cadmium atoms in one layer of the metal. All the atoms lie in one plane. Two principal crystallographic directions are marked

\section{Method of Growing Cylindrical Single Crystals of any Desired Orientation}

In order to test the mechanical properties of ice single crystals, it is desirable to grow cylindrical crystals, several millimetres in diameter, with any desired orientation. In the past, large ice crystals have been grown by Nacken ${ }^{7}$ and Adams and Lewis ${ }^{8}$ using a seed in water, and by Jona and Scherrer, ${ }^{9,}, 10$ who have used controlled cooling and also the method of drawing a crystal from the melt. While these methods can give very large crystals, they are normally not of controlled shape, and could not be used to give the desired cylindrical crystals without difficulty. To overcome this, a method has been developed for growing crystals in glass tubes in water. This method bears some relation to that by which Lavrov 11 obtained polycrystalline specimens for bending experiments; it has been briefly mentioned in a preliminary publication. ${ }^{12}$

If water is allowed to freeze in a bowl, the ice first forms as flat dendrites on the surface of the form shown in Fig. 2. The space between these then fills in to give a flat plate of ice consisting of many crystals each with its optic axis perpendicular to the surface, and then these grow slowly downwards to form columnar crystals. If a glass tube has been inserted in the water and held at an angle, some of the columnar crystals enter the top, and one grows down its length. Thus the ice in such a tube usually consists of a single crystal with its optic axis perpendicular to the surface of the water. By tilting the tube, cylindrical crystals with any desired angle between cylinder and optic axes can be produced. 
This simple method is shown in Fig. 6 (below); it has proved very successful, yielding clear single crystals of the expected orientation. They can be removed by cutting or melting the ice to extract the tubes and then gently warming them until the crystal slides out.

\section{Deformation of Single Crystals}

In order to test these crystals, their ends were frozen into small cups made by turning down brass nuts and soldering eyelets into their ends. These cups were filled with ice-cold water, and the ends of the crystals were put in; the surrounding water was then allowed to freeze into the threads of the cups.

After mounting, the specimens were extended in a single crystal testing machine originally designed by Professor E. Orowan. This machine uses a spring to supply the load necessary to extend the specimen, and measures the strain by an optical lever giving a magnification of 400 . If the specimen deforms uniformly, the length of the spring can be so adjusted that, to the first order,

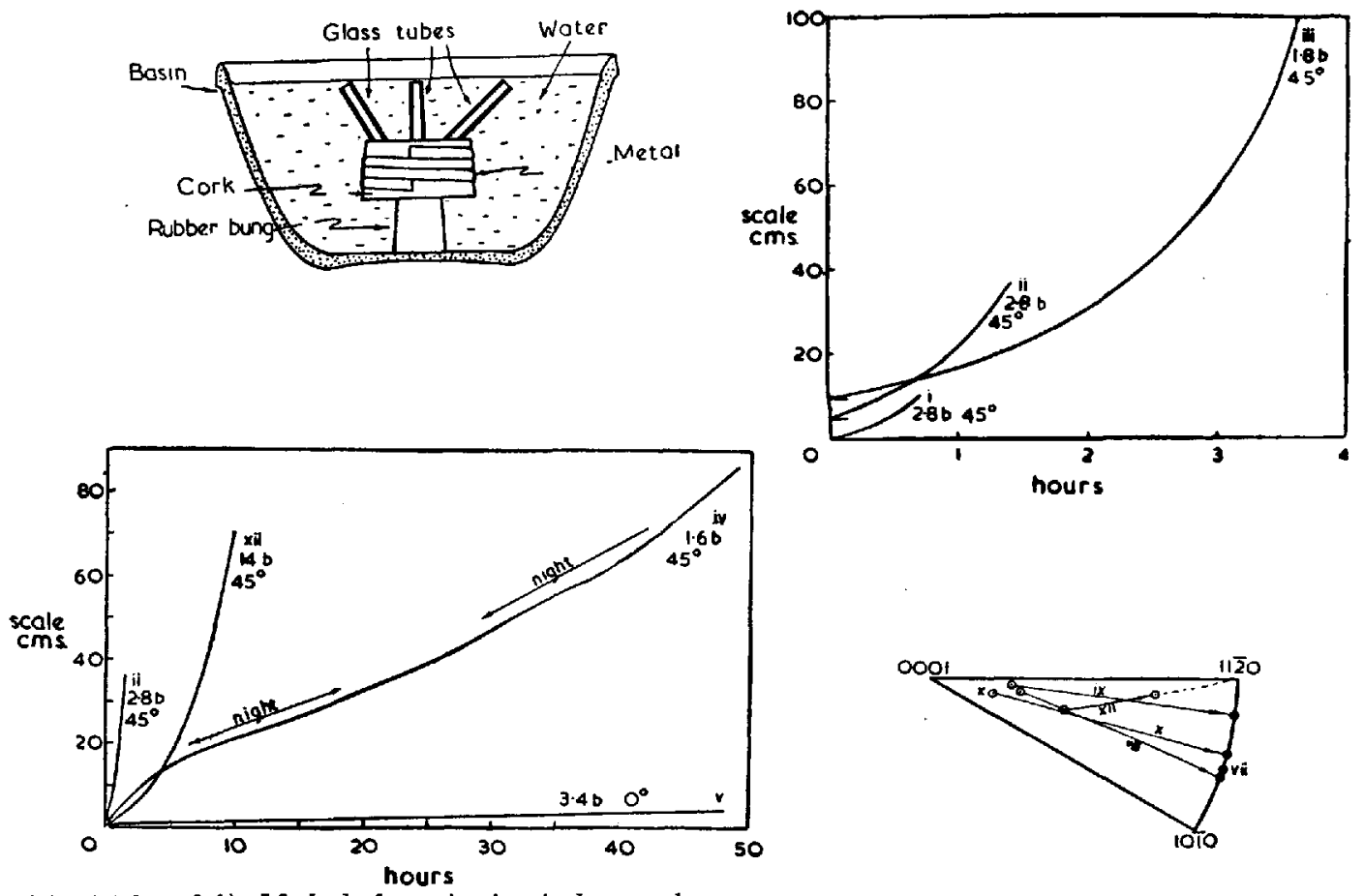

Fig. 6 (above left). Method of growing ice single crystals

Fig. 8 (above right). Creep curves of ice single crystals; the angle between optic and tension axes and the initial tensile stress in bars are marked on each curve

Fig. 9 (below left). Creep curves of ice single crystals. The curves during nights are interpolated

Fig. I3 (below right). Stereographic projection of orientation of tension axes before and after straining

the reduction in length of the spring as the specimen extends reduces the load by just the right amount to keep the resolved shear stress on the glide plane constant. The specimen holder of this machine projected into a refrigerator so that the crystal was pulled at a temperature of $-6^{\circ} \mathrm{C}$.

A total of eleven crystals were pulled; of these eight had the angle between the optic and cylinder axes about $45^{\circ}$, two had this angle $30^{\circ}$ and one specimen $0^{\circ}$. All except the last pulled down to form a tape in the same way as do metal single crystals, but non-uniformly. This means that the load compensation referred to in the last paragraph was of no effect. A photograph of a deformed crystal has already been published ${ }^{12}$; the tape shape is to be expected from a material which is slipping on a single set of glide planes. Large amounts of strain are possible; Fig. 7 
(p. 395) shows a specimen before and after straining. This crystal has deformed inhomogeneously, but not quite as simply as the one shown in the previous paper; two separate necks can be seen, and the tape at the bottom is not flat, but kinked along a vertical line.

In all cases the crystals remained single throughout the test (their detailed structure will be discussed further below), but one specimen which was kept in paraffin at about $-20^{\circ} \mathrm{C}$. started to recrystallize three days after straining, and, in the course of a week, developed several new crystals in the neck.

The strain time curves taken from the specimens are shown in Figs. 8 and 9 (p. 399). In all cases except that of the one specimen where the angle $\theta$ between the optic and cylinder axes was zero, there is a period of accelerating creep. This is to be expected in specimens in which inhomogeneous deformation is occurring, for the resolved stress in the glide direction increases as the deformation proceeds. For this reason no useful deduction can be made from these curves. The tensile stress calculated for the original area is marked against each curve.

The curve for Specimen $\mathrm{v}$, which had $\theta \sim 0^{\circ}$, may appear surprising, as the resolved shear stress on the glide plane would be zero if $\theta$ were exactly $0^{\circ}$. The existence of creep is probably due to a small misorientation, for the tubes were set in the bowl of water with an accuracy of only a degree or two. If it is assumed that $\theta=2^{\circ}$, the creep rate is just what would be expected if a fourth power law of the type found in polycrystals ${ }^{13}$ were valid, and the minimum rate observed in Test iv was the true minimum flow rate. This agreement is probably fortuitous, but the very slow deformation of this specimen is strong evidence against a second deformation mode with its slip direction not in the basal plane. This specimen finally cleaved on the basal plane at some time between 72 and 92 hours from the beginning of the test.

\section{The Search for the Glide Elements}

When a crystal pulls down to a tape, as ice does, the slip plane should tend more and more to become the plane of the tape, while the slip direction should tend to become the direction of the tape. Therefore one way to find the glide elements is to find the orientation of a tape. Of course, if a second glide system starts to act, it may stop these tendencies, but, in general, it will also destroy the tape-like shape, unless the new system has the same glide plane as the original one. Now it is most improbable that a second glide direction in the same plane will become active, as the ratio of the resolved shear stress on any such system to that on the original system will become less and less as time proceeds, and experiments on many sorts of crystals have shown that a second system never acts unless this ratio exceeds unity.

A preliminary experiment was therefore made on a crystal pulled down to a narrow tape (the local strain in the neck was some 600 per cent). Optical examination showed that the plane of the tape was very nearly the basal plane. This not only confirms that the basal plane is the most easy slip plane in ice, but also shows that slip on any other plane must be very much more difficult, as the resolved shear stress on some plane of any other low index group would be very much larger than that on the basal plane by the time a deformation as large as 600 per cent has been reached. Together with the observation on the specimen with $\theta \sim 0^{\circ}$, this shows that no other deformation mode normally occurs in ice.

However, there remains the question of the slip direction. This cannot be determined optically, so $X$-rays were again used. In order to interpret the rather complex pictures expected from heavily deformed crystals, an X-ray pattern was taken from a plate a few millimetres thick cut from the ice formed on the top of a bowl of water. This was grown in the same way as the water dendrite, but the freezing was allowed to continue further. The optic axis was set optically to be parallel to the X-ray beam, using a polarizing attachment previously described. ${ }^{14}$ The resulting $\mathrm{X}$-ray diffraction pattern is given in Fig. 10 (p. 396). It shows that the process of filling in the dendrites has distorted the perfect crystallinity of the ice, as the spots are now somewhat smudged. Apart from this the pattern is almost identical with that of the dendrite, but more intense. The increase of intensity allows us to see more clearly the diffuse spots near the centre. These are due 
to the thermal vibrations of the lattice and are given by the intense $\mathrm{K} \alpha$ lines of $\mathrm{X}$-ray spectrum. Unlike the Laue spots, these diffuse reflexions are rather insensitive to the disorientations in the lattice. In consequence they are extremely useful for finding the approximate orientation of deformed crystals. They have previously been observed in ice by Owston, ${ }^{2}$ who discusses the theory of their formation in detail.

The pulled single crystal was then substituted for the ice plate on the X-ray goniometer and was oriented optically so that the $\mathrm{X}$-ray beam was parallel to the optic axis and the length of the tape was in the vertical plane containing the beam.

The first pulled crystal to be examined gave an easily identifiable pattern, but the vertical direction was almost exactly half-way between a $\langle\mathbf{I} \overline{\mathrm{I}} \mathrm{O} O\rangle$ and $\mathrm{a}\langle\mathrm{I} \overline{\mathrm{I}} \mathrm{O} \mathrm{\rangle}\rangle$ direction, which are the two most probable directions for glide in the basal plane.

In subsequent tests the orientation of the crystal was determined both before and after pulling (two typical patterns are shown in Figs. II and $\mathrm{I} 2$ on page 396), and the resulting orientations were represented on a stereographic net, plotting the direction of the tension axis relative to the crystal axes. On such a plot, the point representing the specimen axis should move, as straining proceeds, towards the point corresponding to the glide direction. Four further specimens were tested; of these three were pulled down to very thin tapes, while the fourth (Specimen xii) was given a smaller deformation.

Fig. I3 (p. 399) shows the results to be confusing. The points corresponding to the specimen axes of ix and $x$ appear to have moved out radially. This would imply slip in the direction of greatest stress in the glide plane irrespective of its crystallographic nature. Specimen xii appeared to slip in $a\langle 1 \mathbf{I} 0\rangle$ direction, while Specimen viii moved in a quite unaccountable way.

As the loci of these points are determined only at their two ends, it remains possible that all the crystals started slipping in a $\langle\mathbf{I} \overline{\mathbf{2}} \mathbf{2} \mathrm{O}\rangle$ direction, but that they deviated later. This should be further checked. Any other interpretation of these results is difficult, unless the behaviour of ice depends on some variable not adequately controlled in these tests.

\section{Asterism and Polygonization of Ice}

The pattern (Fig. 3) obtained from the ice dendrite has small, clear spots, showing that the part traversed by the $\mathrm{X}$-ray beam is a perfect single crystal. When the ice had filled in and thickened (Fig. 10, p. 396) the spots had smeared somewhat. This phenomenon is known as asterism. The single crystals grown from this thickening ice had an even greater spread of orientation (Fig. I I, p. 396), while after deformation the broadening is so great (Fig. I2, p. 396) that the orientation would be difficult to find were it not for the diffuse spots. This spread of orientation is hardly surprising when one considers how a lamella of ice must have been bent as it passed from the virtually undeformed part of the crystal into the neck, and even greater bending may be expected if the crystal is $\mathrm{X}$-rayed, not through the neck, but at the point which is just being pulled out. Such a pattern is shown in Fig. I4 (p. 396), which confirms that even greater misorientations are present.

Figs. 12 and 14 reveal a further point of interest. The broadened spots appear to have split up, at least partially, into new spots. This would correspond to parts of a uniformly bent lattice rearranging themselves into a series of pieces of perfect crystal, each slightly out of orientation with the next, a process called cell formation or polygonization by metal physicists.

Another interesting observation is that Specimen xii, which had been deformed somewhat less than the other crystals, but which nevertheless had extended some roo per cent in the neck, showed comparatively little increase in asterism over the single crystal (Fig. 15, p. 396).

\section{Discussion}

The tension tests on single crystals show that, when a crystal with an angle of about $30^{\circ}$ or $45^{\circ}$ between the optic and tension axes is stretched, it does not deform uniformly, but a small part of its length is strained much more than the surrounding part, and is pulled down to a tape. 
This observation is easily explained; if any part of the crystal deforms more than the adjacent sections, the resolved shear stress on this part is increased more. Thus any slight inhomogeneity in the first deformation tends to get exaggerated. Metal crystals sometimes do pull down uniformly, but only because the rate of work hardening is high enough to compensate the additional stress produced. Inhomogeneities are therefore most likely to occur if the rate of stress increase is large (that is, if the angle between the tension axis and the glide direction is near $45^{\circ}$ ) or if the work hardening is low (which occurs at temperatures near the melting point). These predictions are borne out by the behaviour of metal crystals, as shown by Andrade and Roscoe, ${ }^{15}$ and it is hardly surprising that ice shows inhomogeneous deformation so near to the melting point, where the rate of work hardening is very low. This difficulty can be avoided by choosing angles near $0^{\circ}$ or $90^{\circ}$ between optic and specimen axes, but no detailed work has been done on these cases. Our experiments indicate that no second slip or twinning mode enters in the creep of ice, so that such tests should be feasible.

The attempts to determine the glide elements of ice confirm that the basal plane (ooor) is the glide plane. This is also the glide plane of many hexagonal metals, where, however, there is also a definite glide direction easily detectable (the close packed $\langle\mathrm{I} 1 \overline{2} \mathrm{O}\rangle$ direction). Examination of the crystal structure of ice shows that this is still the probable glide direction, as the atoms near a basal plane are rumpled (unlike the case of metals) and grooves run in $\langle\mathbf{I} \overline{\mathbf{2}} \mathbf{0}\rangle$ directions.

The results obtained are difficult to interpret. It may be that ice near the melting point does not slip along definite crystallographic directions, possibly because many bonds are broken (Bjerrum ${ }^{16}$ ). These may allow glide to occur along a direction of maximum shear stress in the basal plane, which is the plane with fewest bonds perpendicular to it. Another possible explanation is that slip occurs in different proportions on two crystallographically equivalent directions in the basal plane, but if we assume that slip occurs on both systems according to the law connecting resolved shear stress $\tau$ and strain rate $\dot{\gamma}$ of the form found by Steinemann 17

$$
\dot{\gamma}=k \tau^{n}
$$

then the specimen would only apparently slip in the direction of greatest resolved shear stress in the glide plane if $n=\mathrm{I}$, whereas Steinemann found $n$ to be 2 to 4 .

Another interesting observation concerns the Laue asterism. The single crystals, even before straining, showed a certain degree of asterism (Fig. I I), and a diffraction pattern from a point in a specimen where the local deformation was about roo per cent, as measured by the change in orientation, showed little increase in asterism (Fig. 15). This implies that at this stage of the deformation little further misorientation had occurred. Similar observations have frequently been, made on hexagonal metals, but cubic metals normally show large asterisms at a much earlier stage, probably because of the interaction between various possible glide planes.

At large strains, asterism had greatly increased (Figs. 12 and 14 ), which is interesting in itself, but far more interesting is the fact that the spots are now split up into smaller dense spots with a less dense background between. This must mean that the ice consists of many small regions of relatively perfect crystal with a slight difference of orientation between them. The background may be due to the smallness of the crystallites or to connecting regions of bent crystal. Independently of the present work, Steinemann 17 has found splitting of the X-ray asterisms in deformed ice single crystals.

Similar results were obtained by Cahn 18 on annealing strained aluminium, by Greenough, Bateman and Smith ${ }^{19}$ on deforming aluminium at a high temperature, and by Suiter and Wood 20 on an hexagonal metal (magnesium). They are usually attributed to polygonization, a process in which dislocations, which get locked during the deformation and cause the asterism, migrate into walls leaving regions of relatively perfect crystal It seems reasonable to assume that this process occurs also in ice.

\section{ACKNOWLEDGEMENT}

The work described in this paper was carried out while one of us (J.W.G.) was in receipt of a maintenance grant from the Department of Scientific and Industrial Research. 


\section{R E F E R E N C E S}

I. Megaw, H. D. Cell dimensions of ordinary and "heavy" ice. Nature, Vol. I34, No. 3397, I934, p. 900-0r.

2. Owston, P. G. Diffuse scattering of X-rays by ice. Acta Crystallographica, Vol. 2, No. 3, 1949, p. $222-28$.

3. Mason, B. J., and Owston, P. G. Ice crystals of spiral form grown from the vapour. Philosophical Magazine, Ser. 7, Vol. 43 , No. 343 , I952, P. 9 I I-I 2 .

4. McConnel, J. C. On the plasticity of an ice crystal. Proceedings of the Royal Society of London, Vol. 49, No. 299, I891, p. $323-43$.

5. Mügge, O. Ueber die Plasticität der Eiskrystalle. Neues Jahrbuch für Mineralogie, Geologie und Palaeontologie, I 895 , II Bd., p. $211-28$.

6. Tammann, G., and Salge, N. Der Einfluss des Druckes auf die Reibung beim Gleiten längs der Gleitebenen von Kristallen. Neues fahrbuch fïr Mineralogie, Geologie und Pald̈ontologie, Beilage Bd. 57, Abt. A Mineralogie und Petrologie, 1928, p. I17-30.

7. Nacken, R. Über das Wachsen von Kristallpolyedern in ihrem Schmelzfluss. Neues Fahrbuch für Mineralogie, Geologie und Paläontologie, I9I5, II Bd., p. I33-64.

8. Adams, J. M., and Lewis, W. The production of large single crystals of ice. Review of Scientific Instruments, Vol. 5, No. II, I934, p. 400-02.

9. Jona, F., and Scherrer, P. Determinazione delle costanti elastiche del ghiaccio. Nuovo Cimento, Ser. 9, Vol. 8, No. I2, $195 \mathrm{I}$, p. $98 \mathrm{I}-93$.

10. - Die elastische Konstanten von Eis-Einkristallen. Helvetica Physica Acta, Vol. 25, Fasc. 1/2, I952, p. 35-54.

I I. Lavrov, V. V. Vyazkost' l'da v zavisimosti ot temperatury. [The viscosity of ice and its dependence on temperature.] Zhurnal Tekhnicheskoy Fiziki [Journal of Technical Physics], Tom I7, Vyp. 9, 1947, p. 1027-34.

12. Glen, J. W. Experiments on the deformation of ice. Fournal of Glaciology, Vol. 2, No. 12, 1952, p. 111 1 I4.

13. - Rate of flow of polycrystalline ice. Natucre, Vol. 172, No. 4381,1953, p. $721-22$.

14. Perutz, M. F. Polarizing attachment for the microscope of a single crystal X-ray goniometer. Fournal of Scientific Instruments and Physics in Industry, Vol. 26, No. 4, 1949, p. 127-28.

5. Andrade, E. N. da C., and Roscoe, R. Glide in metal single crystals. Proceedings of the Physical Society, Vol. 49, No. 271, 1937, p. 152-76.

16. Bjerrum, N. Structure and properties of ice. Science, Vol. I I 5, No. 2989, I952, p. 385-90.

17. Steinemann, S. Results of preliminary experiments on the plasticity of ice crystals. Fournal of Glaciology, Vol. 2, No. 16, 1954, p. 404-12.

18. Cahn, R. W. Slip and polygonization in aluminium. Fournal of the Institute of Metals, Vol. 79, Pt. 3, 195 I, p. I29-58.

19. Greenough, G. B., Bateman, C. M., and Smith, E. M. X-ray diffraction studies in relation to creep. Fournal of the Institute of Metals, Vol. 80, Pt. 10, 1952, p. 545-50.

20. Suiter, J. W., and Wood, W. A. Deformation of magnesium at various rates and temperatures. Fournal of the Institute of Metals, Vol. 81, Pt. 4, 1952, p. 181-88.

\section{PAUL N I G GLI ( I 888 - I 953 )}

IN the death of Professor Niggli on I 3 January 1953 the scientific world lost an outstanding teacher and scientist, and glaciological study a stalwart supporter.

Director of the Mineralogical-Petrographical Department of the Eidgenössische Technische Hochschule at Zürich, his text-books on mineralogy and petrography and his numerous papers on a wide range of subjects, including education, politics and the history of science, will be an everlasting memorial to his personality and activity.

It is not so well known that for twenty years Niggli was in close contact with snow and ice research. He wrote the introduction to the first fundamental publication of the Eidgenössisches Institut für Schnee- und Lawinenforschung, Weissfluhjoch, entitled Der Schnee und seine Metamorphose, I939, outlining the background and the aims of Swiss snow research. For the inauguration of the new Institute in 1943 he gave a most impressive address on the beginning and development of snow and glacier research in the Swiss Alps (Schnee- und Gletscherforschung in der Schweiz, Mitteilung, Nr. I). With his profound analysis of scientific discovery in the Swiss Alps he freed the new Institute from a merely technical programme and linked it to the uninterrupted tradition of Alpine science.

In the literature of snow Niggli's name appears but rarely. Nevertheless, a good deal of the work done by the research workers at the Weissfluhjoch profited by his valuable support.

As a member of the Schweizerische Schnee- und Lawinenforschungs Kommission he always emphasized the need for crystallographical investigations, but, never blind to practical requirements, he was always ready with advice upon any "applied problem" including organization, personnel and finance.

Niggli's intellect was universal, and he was engaged in innumerable tasks and duties. We may wonder, therefore, why the comparatively narrow branch of snow and ice research was honoured in receiving so great a share of his devotion and energy. Niggli's deep affection for the glacier- 